\begin{tabular}{c} 
Volume and Issues Obtainable at Center for Sustainability Research and Consultancy \\
Journal of Business and Social Review in Emerging Economies \\
ISSN: 2519-089X \& ISSN (E): 2519-0326 \\
Volume 7: Issue 2 June 2021 \\
JSR \\
Journal homepage: www.publishing.globalcsrc.org/ibsee \\
\hline
\end{tabular}

\title{
The Statistical Analysis of Factors Explaining the Intention of Public for Blood Donation in Jamshoro, Sindh
}

*Nazia Parveen Gill, Assistant Professor, Department of Statistics, University of Sindh, Jamshoro, Pakistan

Fozia Parveen Panhwar, MS Scholar, Department of Statistics, University of Sindh, Jamshoro, Pakistan Sunbul Naeem Cheema, PhD Scholar, Department of Management Science, the Islamia University, Bahawalpur, Pakistan

Raja Muhammad Ilyas, Department of Statistics, University of Sindh, Jamshoro, Pakistan

*Corresponding author's email address: nazia.gill@usindh.edu.pk

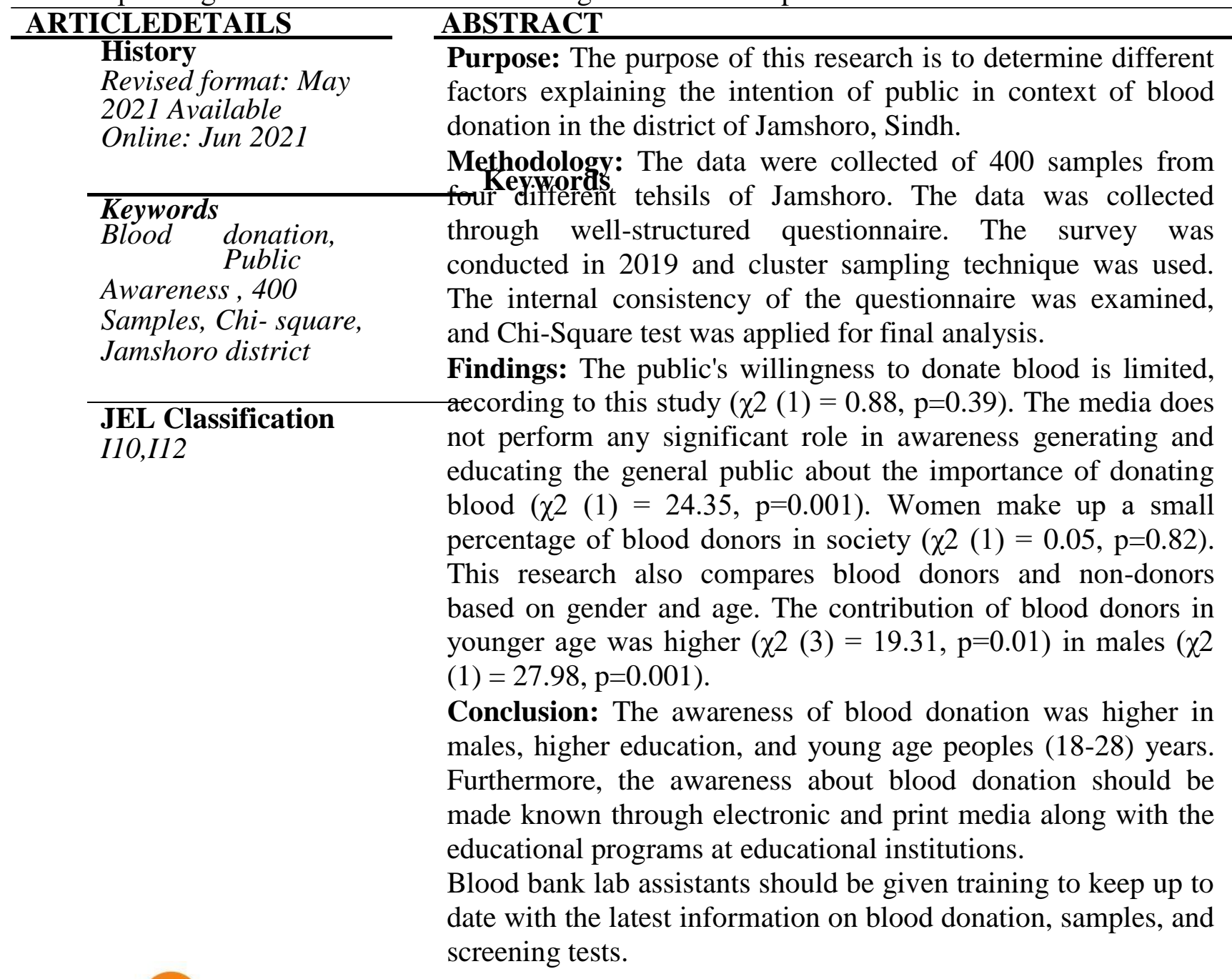


Recommended citation: Gill, N. P., Panhwar, F.P., Cheema, S.N., Ilyas, R. M., (2021). The Statistical Analysis of Factors Explaining the Intention of Public for Blood Donation in Jamshoro, Sindh. Journal of Business and Social Review in Emerging Economies, 7(2), 231-238

\section{Introduction}

Human blood cannot be substituted since it is an integral component of human life (Agrawal et al., 2013). Every year more than 5 million people die because of violence and injuries (WHO, 2009), road accident are the second major cause of death worldwide (Motamedi et al., 2014), more than 536000 women died each year due to pregnancy and child birth (Shah \& Say, 2007), majority of them in developing countries

in all these condition the timely access to safe blood can save millions of life in these conditions and can prevent patients from severe illness. Therefore, the need of safe blood is increasing day by day. Blood donations are encouraged by surgeons and physicians in order to save lives and extend life expectancy. Blood transfusions save millions of lives every year all over the world. (Sabu et al., 2011), however the quality and safety of donated blood is still a major concern in developing countries (Roberts, 2016; WHO, 2008).

Blood donors are divided into three groups: first, non-paying (volunteer), second, family and friend donors, and third, paid donors. A volunteer blood donor is anyone who donates blood without expecting something in return, including money or something that could be used as a replacement for money. In an emergency, family and friends donate blood for a specific patient. Paid donors are compensated in cash or in kind for their blood donation. (Politis, 2000). According to WHO (World Health organization) data collected of 324 blood banks, there were $15.4 \%$ voluntary blood donors and 84.6 ere family/replacement donors (WHO, 2004). In Pakistan majority of blood donors comes from family and relatives. This practice is not good as sometimes donors donate their blood under family pressure and hide their disease. Blood donated from family and relatives have a higher risk of Transfusion transmitted infections (Jain et al, 2012). In Pakistan, there is an urgent need for blood donation in public to motivate and educate them through print and electronic media and through educational programs. The aim of this study is to figure out what factors influence people's willingness to donate blood in Jamshoro, Sindh.

\section{Objectives of the Study}

1- To investigate the factors that influence the public's awareness, attitude, and practice of blood donation.

2- To determine the blood donation facilities those are available for public.

3- To compare the ratio of blood donors to non-donors in the general population.

4 To propose any motivating factors that will help to enhance the process of blood donation in the future.

\section{Hypothesis}

$\mathrm{H}_{0} 1$ : The awareness level is limited in public about the importance of blood donations.

$\mathrm{H}_{0}$ 2: The media is contributing with an important role in educating general public about the importance of blood donation.

$\mathrm{H}_{0} 3$ : After every three months blood donation can be done.

$\mathrm{H}_{0} 4$ : Women make up a small percentage of blood donors in society.

\section{Research Methodology and Data Analysis}

This study includes primary data of 400 participants. Data collection was done from four districts of Jamshoro including, Kotli Taluka, Sehwan Taluka, Manjhand Taluka and Tando Bula Khan Taluka. Sampling technique that was used in this research was cluster sampling. The research tool was a wellstructured questionnaire. The survey was conducted in 2019 from public of mentioned tehsils of Jamshoro, Sindh.

\section{Sample Size}


The statistical formula of Taro Yamane (1967) is used to calculate the sample size of public (Yamane, 1967).

Where

$$
\mathrm{n}=\frac{\mathrm{N}}{1+\mathrm{N}(\mathrm{e})^{2}}
$$

$\mathrm{n}=$ Size of Sample

$$
\begin{gathered}
\mathrm{N}=\text { size of Population e=Error } \\
\mathrm{n}=\frac{993142}{1+(993142)(0.05)^{2}}=\frac{993142}{2482.855}=400
\end{gathered}
$$

Before beginning the statistical data analysis, the internal accuracy of the questionnaire was tested using the Cronbach alpha method of reliability analysis. We obtained a Cronbach alpha value of $\alpha=0.92$, indicating that our questionnaire is valid for further study. The analysis of data was done in SPSS statistical package for social science ( 24 version), and value of $p \leq 0.05$ considered significant statistically. Initially descriptive statistics was used and finally Chi- Square test was applied for testing of

\begin{tabular}{|c|c|c|c|c|c|c|}
\hline & \multicolumn{2}{|c|}{$(\mathrm{N}=200)$ Male } & \multicolumn{2}{|c|}{$(\mathrm{N}=200)$ Female } & \multicolumn{2}{|c|}{$(\mathrm{N}=400)$ Total } \\
\hline & $\mathrm{n}$ & Percentage & $\mathrm{n}$ & Percentage & $\mathrm{n}$ & Percentage \\
\hline \multicolumn{7}{|l|}{ A. Marital Status } \\
\hline Married & 98 & 49 & 63 & 31.5 & 161 & 40.3 \\
\hline Unmarried & 102 & 51 & 137 & 68.5 & 239 & 59.8 \\
\hline \multicolumn{7}{|l|}{ Age } \\
\hline $18-28$ & 106 & 53 & 108 & 54 & 214 & 53.5 \\
\hline $28-38$ & 74 & 37 & 77 & 38.5 & 151 & 37.8 \\
\hline $38-48$ & 20 & 10 & 15 & 7.5 & 35 & 8.8 \\
\hline \multicolumn{7}{|c|}{ B. Educational Qulaification } \\
\hline Primary & 35 & 17.5 & 46 & 23 & 81 & 20.2 \\
\hline Matriculation & 27 & 13.5 & 17 & 8.5 & 44 & 11 \\
\hline Intermediate & 43 & 21.5 & 47 & 23.5 & 90 & 22.5 \\
\hline Graduation & 55 & 27.5 & 47 & 23.5 & 102 & 25.5 \\
\hline Any others & 30 & 15 & 18 & 9 & 48 & 12 \\
\hline Illiterate & 10 & 5 & 25 & 12.5 & 35 & 8.8 \\
\hline \multicolumn{7}{|l|}{ C. Occupation } \\
\hline Student & 66 & 33 & 50 & 25 & 116 & 29 \\
\hline Goverment employed & 21 & 10.5 & 4 & 2 & 25 & 6.2 \\
\hline Private employed & 39 & 19.5 & 20 & 10 & 59 & 14.8 \\
\hline Self employed & 21 & 10.5 & 24 & 12 & 45 & 11.2 \\
\hline UN employed & 28 & 14 & 47 & 23.5 & 75 & 18.8 \\
\hline Others & 25 & 12.5 & 55 & 27.5 & 80 & 20 \\
\hline
\end{tabular}
hypothesis. Table 1. Represents the basic demographic data of the participants.

Table: 01. Demographic data of the participants

\section{Blood donors and Non-donors}

Among 400 participants, the majority of respondents (72\%) were non-donors. Anxiety, low hemoglobin levels, and a lack of knowledge were the key reasons for not donating blood. The pie chart of blood donors and non-donors with respect to gender is presented in figure 1. The respondents donating blood in majority were males $(20 \%)$. 


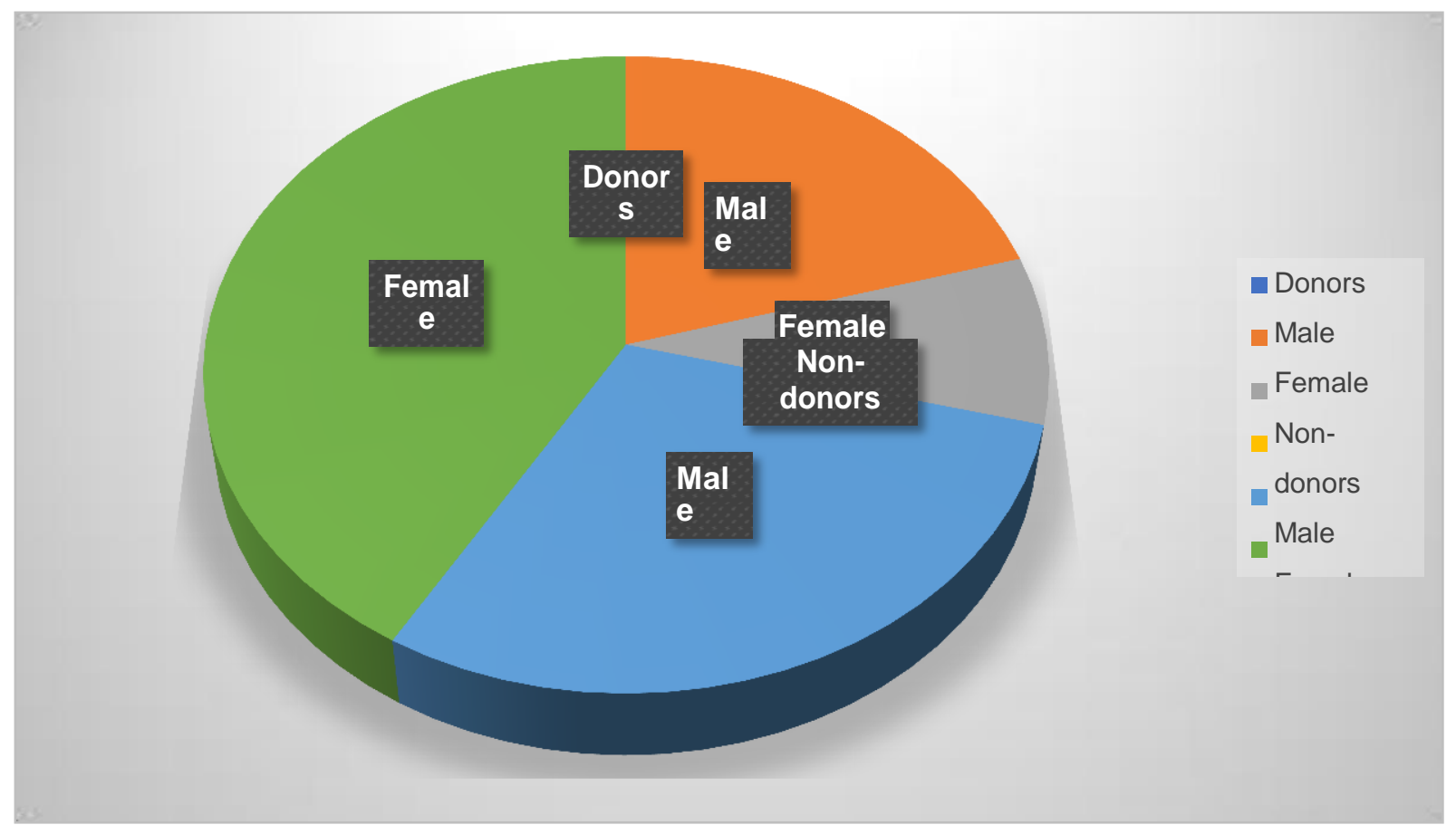

Figure 01. Pie Chart of Blood donors and Non-donors

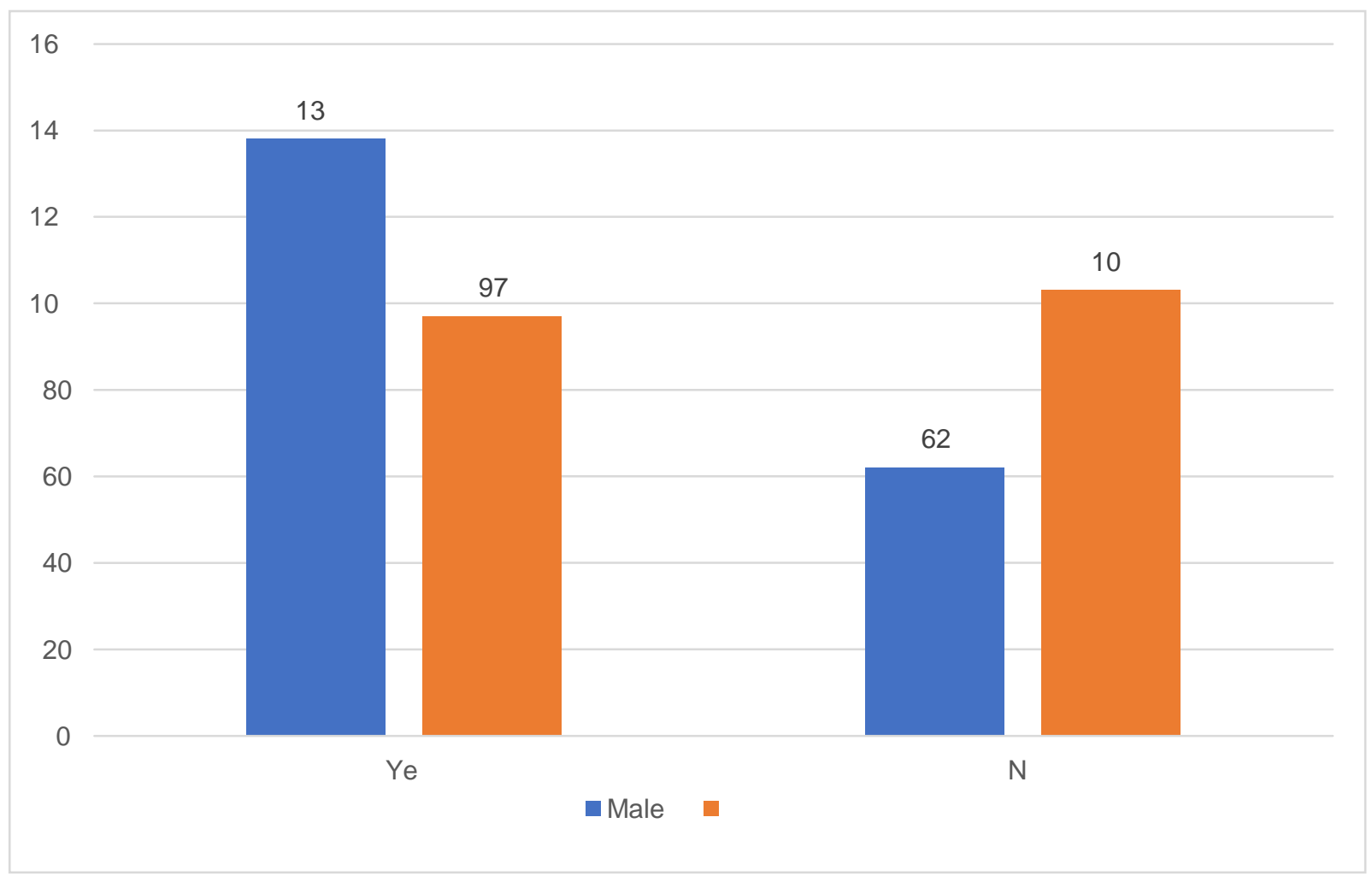

Figure 02. Bar chart of participants who come to know about blood donation from their family.

The above bar chart shows that the majority of blood donors 235 (58.8\%) learn about blood donation from their families (figure 2.). Another result of our study revealed that majority of respondent agreed $233(58.3 \%)$ members in family makes decision whether to donate blood or not.

\section{Hypothesis Testing}

Testing of hypothesis was performed using the chi-square test and following results were obtained

$\mathbf{H}_{\mathbf{0}} \mathbf{1}$ : The awareness level is limited in general public about the importance of blood donations.(see table 2). 
Table 02: Chi-Square table of hypothesis: The awareness level is limited in general public about the importance of blood donations.

\begin{tabular}{|c|c|c|c|}
\hline \multicolumn{3}{|c|}{ CHI-SQUARE TEST } \\
\hline & $\begin{array}{c}\text { Calculated Value of Chi- } \\
\text { Square (Critical value 3.84) }\end{array}$ & d.f & $\begin{array}{c}\text { p-value } \\
\text { (Level of } \\
\text { significance=0.05) }\end{array}$ \\
\hline Pearson Chi-Square & 0.88 & 1 & 0.39 \\
\hline
\end{tabular}

According to the results in the Chi-Square test table it is indicated that the value of $\mathrm{p}$ exceeds the point of significance of 0.05 , i.e. $\chi^{2}(1)=0.88, \mathrm{p}=0.39$, so there is an evidence to support the null hypothesis, and we conclude that public knowledge of blood donation is minimal.

$\mathbf{H}_{\mathbf{0}}$ 2: The media is contributing with an important role in educating general public about the importance of blood donation.

Table 03. Chi-Square table of hypothesis: The media is contributing with an important role in educating general public about the importance of blood donation.

\begin{tabular}{|l|l|l|l|}
\hline \multicolumn{4}{|c|}{ Chi-Square Test } \\
\hline & $\begin{array}{l}\text { Calculated value of chi- } \\
\text { square (Critical value } \\
3.84)\end{array}$ & d.f & $\begin{array}{c}\text { p-value } \\
\text { (Level of } \\
\text { significance=0.05) }\end{array}$ \\
\hline Pearson Chi-Square & 24.35 & 1 & .001 \\
\hline
\end{tabular}

According to the Chi-Sure results in table 03, it is indicated that since our value of $\mathrm{p}$ is smaller than 0.05 , i.e. $\chi^{2}(1)=24.35, p=0.001$, so there is validation to refuse the null hypothesis, and we concludes that media does not play a significant part educating people in context of donating blood.

Ho3: After every three months blood donation can be done. (See table 4).

Table 04. Chi-Square table of hypothesis: After every three months blood donation can be done

\begin{tabular}{|c|c|c|c|}
\hline \multicolumn{4}{|c|}{ CHI-SQUARE TEST } \\
\hline & $\begin{array}{l}\text { Calculated Value of chi- } \\
\text { square (Critical value } 3.84 \text { ) }\end{array}$ & d.f & $\begin{array}{c}\mathrm{p} \text {-value } \\
(\text { Level of } \\
\text { significance }=0.05)\end{array}$ \\
\hline Pearson Chi- Square & 0.35 & 1 & 0.6 \\
\hline
\end{tabular}

Based on information in the test table of Chi-Square, the value of $\mathrm{p}$ is larger than the significance level $=0.05$ i.e. $\chi^{2}(1)=0.35, p=0.6$, so this is the proof of accepting null hypothesis. This research concludes that donation of blood can be done after every tree months.

$\mathbf{H}_{0}$ 4: Women make up a small percentage of blood donors in society.

Table 05: Chi Square table of hypotesis testing: Women make up a small percentage of blood donors in society. CHI-SQUARE TEST 


\begin{tabular}{|l|l|l|l|}
\hline & $\begin{array}{l}\text { Calculated Value of chi-square } \\
\text { (Critical value 3.84) }\end{array}$ & d.f & $\begin{array}{c}\text { p-value } \\
\text { (Level of } \\
\text { significance }=0.05)\end{array}$ \\
\hline Pearson Chi-Square & 0.05 & 1 & 0.82 \\
\hline
\end{tabular}

According to the test table of Chi-Square results the value of $\mathrm{p}$ higher than the significance level $(0.05)$, i.e. $\chi^{2}(1)=0.05, p=0.82$, so the evidence proposes that the null hypothesis is accepted, while concluding that the quantity of women towards blood donors in general public is low.

\section{Age and Gender Comparison between Blood Donors and Non Blood Donors}

Table 05. Comparison between Blood Donors and Non Blood Donors (Age)

\begin{tabular}{|c|c|c|c|c|c|c|}
\hline \multirow{2}{*}{ Age Groups } & \multicolumn{2}{|c|}{$\operatorname{Donors}(n=116)$} & \multicolumn{2}{|c|}{ Non-donors $(n=284)$} & \multirow{2}{*}{ Chi-Square } & \multirow{2}{*}{ P-value } \\
\hline & Number & Percentages & Number & Percentage & & \\
\hline $18-28$ & 83 & 71.6 & 143 & 50.4 & \multirow{5}{*}{19.31} & \multirow{5}{*}{0.001} \\
\hline $29-35$ & 27 & 23.3 & 88 & 31.0 & & \\
\hline $35-43$ & 5 & 4.3 & 28 & 9.9 & & \\
\hline 44 and above & 1 & .9 & 25 & 8.8 & & \\
\hline Total & 116 & 100.0 & 284 & 100.0 & & \\
\hline
\end{tabular}

According to table 6 of the Chi-Square test, the attendance of blood donors in the younger age group (18-28) years is higher than in remaining groups of age. The notified disparity was very significant statistically $(\mathrm{p}=0.001): \chi^{2}(3)=19.31$. When we measured the number of blood donors and nondonors by gender, we discovered that males had a higher percentage of blood donors than females. The gender gap that was deduced was statistically important which is $\chi^{2}(1)=27.98, p=0.001$.

\section{Discussion}

In our survey, the majority of respondents $(71 \%)$ were non-donors, with anxiety, low hemoglobin levels, and a lack of knowledge being the key reasons for not donating blood. We discovered that the greater part of donor was males $(20.5 \%)$. Similarly, the greater part of blood donor was falling in the age group of 18 28 with $(53.5 \%)$ are between the ages of 18 and 28 . Graduates were in the majority of the respondents $(25.5 \%)$.

Moreover, greater number of participants $(58.3 \%)$ accepted that men or male guardian decides whether to donate blood or not. A research indicated that among blood donors (89\%) of donors were males (Alam, et al., 2004). Our first hypothesis was confirmed by a chi-square test, which showed that public knowledge of blood donation is low.

The study's first hypothesis was verified and tested. So, the measured value of chi square was significant. The $\mathrm{p}$ value was also significant while accepting the null hypothesis. Overall, it was proposing that public understanding about donating blood is extremely low. Our second hypothesis found that the media can contribute significantly in educating general public about importance of donating blood. So, the $\mathrm{p}$ value and chi square results validated the rejection of null hypothesis and concluding that media in all forms does not contribute effectively to educate people in the context of blood donation. According to Maqbool, et al., (2004), there are misconceptions about blood donation 
among Saudi citizens, who need proper education and encouragement through the dissemination of blood donation information, especially through electronic media (Sundar, et al., 2010).

The third hypothesis proposes that donation of blood can be done after every three months. So as per the $\mathrm{p}$ value of significance chi square results null hypothesis is accepted and it is concluded that donation of blood can be done after every three months. The fourth hypothesis was about low proportion of women in blood donation. So, the statistical results with $\mathrm{p}$ value and chi square results, the null hypothesis is accepted and concluding that number of women is very low among public donating blood.

Moreover, this research shows that non donors and donors of blood are different in context of age and gender. Men donate more blood as compared to women. Age group of 18-28 donates more blood as compared to other age groups. These statements are also verified statistically in this research.

\section{Conclusion}

The greater proportion of blood donors were male men, and the majority of respondents decided that male family members make the decision whether or not to blood donate. The majority of donors are between the ages of 18 and 28. Graduates made up the majority of the respondents. Most of the donors choose to give blood only to their friend and family and friends. The majority of participants were not donor of blood, and the most common reasons for this were the low hemoglobin level, fear and lack of awareness. Blood donation awareness was low among the general public. The media as such does not contribute active role in sensitizing and educating general public about the benefits and importance of donating blood. Donating blood every three months is good for your wellbeing, as shown by the results. Women make up a small percentage of blood donors in society.

\section{Recommendations.}

According to the results and findings this research proposed following recommendations.

i. Government authorities should help out women by holding numerous campaigns and activities to raise awareness about blood donation.

ii. Training programs for blood bank lab assistants should be designed to keep them up to date with the latest information on blood donation and sample screening tests.

iii. Blood donation can be made more widely known via print and electronic media.

iv. In order to raise awareness of blood donation, educational activities such as workshops, lectures, and discussions should be launched in schools, colleges, and universities.

v. More blood banks with well-accredited and up-to-date equipment should be established by the government.

\section{References}

Agrawal, Amit, Aseem, K., Tiwari, Alok, A., \& Kalra, R. (2013) "Knowledge, attitude and practices of people towards voluntary blood donation in Uttarakhand." Asian journal of transfusion science 7, no. 159.

Alam, M., \& El Din Masalmeh, B. (2004). Knowledge, attitudes and practices regarding blood donation among the Saudi population. Saudi medical journal, 25(3), 318-321.

Jain, R., \& Gupta, G. (2012). Family/friend donors are not true voluntary donors. Asian journal of transfusion science, 6(1), 29.

Motamedi, M. H. K., Dadgar, E., \& Ebrahimi, A. (2014). Curbing Road Traffic Accidents-The Major Cause of Facial Fractures. International journal of emergency mental health, 16(2), 326-7.

Politis, C. (2000). Blood donation systems as an integral part of the health system. Arch Hellen Med, 17(4), 354-357.

Roberts, D. J., Field, S., Delaney, M., \& Bates, I. (2016). Problems and approaches for blood transfusion in the developing countries. Hematology/Oncology Clinics, 30(2), 477-495.

Sabu, K. M., Remya, A., Binu, V. S., \& Vivek, R. (2011). Knowledge, attitude and practice on blood 
donation among health science students in a university campus, South India. Online Journal of Health and Allied Sciences, 10(2).

Sundar, P., Sangeetha, S. K., Seema, D. M., Marimuthu, P., \&Shivanna, N. (2010). Pre-donation deferral of blood donors in South Indian set-up: An analysis. Asian journal of transfusion science, 4(2), 112.

World Health Organization. (2008). Universal access to safe blood transfusion (No. WHO/EHT/08.03). World Health Organization.

World Health Organization. (2008). Universal access to safe blood transfusion (No. WHO/EHT/08.03). World Health Organization.

World Health Organization. Dept. of Violence, Injury Prevention, World Health Organization. Violence, Injury Prevention, \& World Health Organization. (2009). Global status report on road safety: time for action. World Health Organization.

Yamane, T. (1967). Statistics: An introductory analysis (No. HA29 Y2 1967). 